Article

\title{
Miscibility Studies of Hyaluronic Acid and Poly(Vinyl Alcohol) Blends in Various Solvents
}

\author{
Katarzyna Lewandowska (iD)
}

Faculty of Chemistry, Nicolaus Copernicus University in Torun, Gagarin 7, 87-100 Toruń, Poland; reol@umk.pl

Received: 18 September 2020; Accepted: 20 October 2020; Published: 23 October 2020

check for updates

\begin{abstract}
In this study, blends based on hyaluronic acid (HA) and poly(vinyl alcohol) (PVA) were characterized by the viscometric method, steady shear rheological tests and FTIR spectroscopy (Fourier Transform Infrared Spectroscopy). Viscometric studies showed the miscibility of HA and PVA in distilled water: $0.1 \mathrm{~mol} \mathrm{dm}^{-3} \mathrm{NaCl}$ and $0.1 \mathrm{~mol} \mathrm{dm}^{-3} \mathrm{HCl}$. The method proposed by Garcia et al. was applied to assess the miscibility of polymers, while $\Delta[\eta]$ and $\Delta b$ were introduced to determine of miscibility from the Huggins plots. The viscometric data showed that the attractive forces of $\mathrm{HA}$ and PVA were dominant when dissolved in $0.1 \mathrm{~mol} \mathrm{dm}^{-3} \mathrm{NaCl}$ and $0.1 \mathrm{~mol} \mathrm{dm}{ }^{-3} \mathrm{HCl}$, while, in distilled water, repulsive forces played the leading role. All polymer solutions were well characterized using a power law model, and exhibited non-Newtonian behavior with pseudoplasticity increasing with the increasing weight fraction of $\mathrm{HA}$ in $0.1 \mathrm{~mol} \mathrm{dm}^{-3} \mathrm{NaCl}$ and $0.1 \mathrm{~mol} \mathrm{dm}^{-3} \mathrm{HCl}$. FTIR studies exhibited the formation of new intermolecular interactions between HA and PVA via hydrogen bonding.
\end{abstract}

Keywords: polymer blends; poly(vinyl alcohol); hyaluronic acid; rheological properties

\section{Introduction}

Hyaluronic acid (HA) is a natural macromolecule isolated from natural sources such as bacteria (Streptococcus equi), rooster combs and others [1,2]. It is a class of the nonsulfated glycosaminoglycan, and consists of repeating disaccharide units of D-glucuronic acid and N-acetyl glucosamine linked by $\beta(1,4)$ and $\beta(1,3)$ glucosidic bonds [1-4]. HA possesses interesting properties such as biodegradability, non-toxicity for living organisms, solubility in aqueous solutions, bioactivity and biocompatibility, which have resulted in increased interest in the material's potential medical and cosmetic uses, e.g., in the fields of tissue engineering, applications in wound healing, drug delivery, artificial skin, and as an ingredient in cosmetics that provides anti-aging and moisture-supplying effects to the skin [3,5-13]. The drawbacks of using HA as a biomaterial is its rapid degradation and poor mechanical stability [10]. There are several types of processes that can improve the polymeric structure and properties of HA. One such method involves mixing with other components such as proteins, polysaccharides, synthetic polymers, hydroxyapatite, nanofillers and inorganic and/or organic compounds [10,14,15].

In this study, blends composed of HA with poly(vinyl alcohol) (PVA) at different ingredient ratios have been prepared as materials designed for biomedical and cosmetic applications. PVA is a water-soluble, non-ionic synthetic polymer. Its ease of preparation, as well as good biocompatibility, biodegradability and physiological inactivity, promoted the widespread use of PVA in diverse areas such as food, drug delivery systems, cosmetics and other medical and industrial applications [16-20]. Therefore, HA properties can be improved by blending hyaluronic acid with PVA. These blends can be used to produce implants, wound dressings and in drug delivery $[13,21]$. Additionally, the viscosity behavior of polymers and their blends are essential for many applications. In the case of cosmetic and food usage, viscosity behavior at different temperatures is essential in order to design proper formulations and check their applicability under various conditions. Based on rheological 
studies, one can design a product with tailor-made properties for specific uses, for example, tissue engineering purposes.

Several reports examined HA blends with PVA as films [21], gels [22-24], cryo-gel membranes [25-27] and blends based on HA and poly(vinyl alcohol)-borax association (PVAs) [28]. They showed that the chemically cross-linked PVA/HA hydrogels can be attractive materials for tissue engineering [22]. In the case of HA/PVA cryo-gels, modification of PVA hydrogels is achieved through the addition of HA which enhances the properties and bioactivity of films, compared with pure PVA hydrogel [25].

The purpose of our study was to investigate the influence of various solvents on the physical properties of HA/PVA blends. The miscibility, structure and rheological properties were characterized based on the viscometric technique, steady shear rheological measurements and FTIR spectroscopy. Miscibility is an important aspect for the preparation of new materials based on the blending of two polymers. The properties of these materials depend on the specific interactions between the ingredients. If such interactions are possible, the blending of chemically different polymer components can occur even at the molecular level, and the properties of the blend can exhibit a synergistic effect. The estimation of the miscibility in polymer blend solutions comprising a common solvent for polymer $A$ and $B$ relies on the comparison of the experimental interaction parameters with ideal values. Reports have shown that a positive deviation between the experimental and ideal values indicates a miscible system in which attractive forces are dominant $[15,19,29]$, whereas negative deviation indicates an immiscible system in which repulsive forces play a leading role. To the best of the author's knowledge, the miscibility of HA/PVA in various solvents by the viscometric method has yet to be investigated. The viscometric method is a simple, quick and inexpensive evaluation approach for the miscibility of polymers in solution.

\section{Materials and Methods}

\subsection{Materials}

Unless otherwise stated, all materials, chemicals and reagents used in this work were supplied by Sigma-Aldrich (Poznan, Poland), Chempur (Piekary Śląskie, Poland) and POCh (Avantor, Gliwice, Poland). Poly(vinyl alcohol) with a $99 \%$ degree of hydrolysis (DH) and an average molecular weight viscosity of 130,000 was used. HA powder with an average molecular weight viscosity of 8000 was used. All chemicals were of analytical grade and used as received without further purification.

Preparation of polymer solutions and thin films consisted of the polymer sample being dissolved in distilled water: $0.1 \mathrm{~mol} \mathrm{dm}^{-3} \mathrm{NaCl}$ and $0.1 \mathrm{~mol} \mathrm{dm}^{-3} \mathrm{HCl}$. The solutions of $\mathrm{HA}$ and PVA were mixed at different proportions (75/25, 50/50 and 25/75). Thin films were obtained by the solution casting method. The polymer and blend solutions were poured onto a glass plate, covered with polyethylene film and evaporated at room temperature $(298 \mathrm{~K})$ for $24 \mathrm{~h}$. The films were then dried at $323 \mathrm{~K}$ for $24 \mathrm{~h}$ under a vacuum and stored in a desiccator. All films had a similar thickness of approx. $20 \mu \mathrm{m}$.

\subsection{Viscometric Studies}

Viscometric studies of diluted solutions $\left(c<1.5 \%\right.$ ) were conducted at $25 \pm 0.1{ }^{\circ} \mathrm{C}$ using an Ubbelohde capillary viscometer in a controlled thermostatic bath. Each stock polymer solution with known weight was added to the viscometer and flow time was measured at constant temperature within $\pm 0.1{ }^{\circ} \mathrm{C}$. A certain amount of solvent was added to the solution successively to obtain a concentration gradient ( 5 various concentrations). Then, the flow time of the solvent was measured. The flow time of each solution was taken as the average of several readings. The specific viscosity of dilute polymer solution was calculated by Equation (1):

$$
\eta_{s p}=\frac{t-t_{0}}{t_{0}}
$$


where $t$ is the flow time of the polymer solution and $t_{0}$ is the flow time of the solvent.

The values of the miscibility parameter and intrinsic viscosity were calculated using the Huggins equation from solutions of several concentrations [30,31]. The miscibility was evaluated by a comparison of the experimental and ideal values of $b_{m}$ and $[\eta]_{m}$. The values of miscibility parameters were obtained using the same methods as described in [29]. In previous papers [29,32], the main aspects of the use of the method proposed by Garcia et al. [33] to investigate of miscibility in dilute solutions are described. Briefly, the experimental interaction parameter was calculated using Equation (2):

$$
\frac{\left(\eta_{s p}\right)_{m}}{c_{m}}=[\eta]_{m}^{\exp }+b_{m}^{\exp } c_{m}
$$

where $\left(\eta_{s p}\right)_{m}$ is the specific viscosity of the polymer blend (dimensionless), $\left(_{s p}\right)_{m} / c_{m}$ is the reduced viscosity $(\mathrm{dL} / \mathrm{g}), c_{m}$ is the total concentration of the polymer blend $(\mathrm{g} / \mathrm{dL}),[\eta]_{m}^{\text {exp }}$ is the experimental intrinsic viscosity $(\mathrm{dL} / \mathrm{g})$ and $b_{m}^{\text {exp }}$ is the experimental interaction parameter $(\mathrm{dL} / \mathrm{g})^{2}$. The slope and intercept of the graph (the reduced viscosity $\left(\eta_{s p} / c\right)$ vs. total concentration $(c)$ ) gave the values of $b_{m}^{\text {exp }}$ and $[\eta]_{m}^{\text {exp }}$, respectively. The ideal interaction parameter was described by Equation (3):

$$
b_{m}^{i d}=w_{A} b_{A}^{2}+w_{B} b_{B}^{2}
$$

where $b_{m}^{i d}$ is the ideal interaction parameter $(\mathrm{dL} / \mathrm{g})^{2}, w_{A}$ and $w_{B}$ are the weight fractions of polymers A and $\mathrm{B}$, respectively, $b_{A}$ and $b_{B}$ are the interaction parameters of each individual polymer. The miscibility criterion is as follows:

if $\Delta b_{m}=b_{m}^{\exp }-b_{m}^{i d}>0$ the polymer blend is miscible,

if $\Delta b_{m}=b_{m}^{e x p}-b_{m}^{i d}<0$ the polymer blend is immiscible.

According to Garcia's method [33], another criterion based on the experimental and ideal values of the intrinsic viscosity $\left([\eta]_{m}\right)$ was proposed. The experimental value $\left([\eta]_{m}^{\text {exp }}\right)$ was estimated from the intercept of the graph according to Equation (2). The $[\eta]_{m}^{i d}$ value was described by Equation (4):

$$
[\eta]_{m}^{i d}=w_{A}[\eta]_{A}+w_{B}[\eta]_{B}
$$

where $[\eta]_{A}$ and $[\eta]_{B}$ are the intrinsic viscosity $(\mathrm{dL} / \mathrm{g})$ of polymers $\mathrm{A}$ and $\mathrm{B}$, respectively. Thus, if $\Delta[\eta]<$ 0 , the polymer blend is miscible, and if $\Delta[\eta]>0$, the polymer blend is immiscible.

\subsection{Steady Shear Measurements}

Rheological measurements of polymer solutions were conducted using a Bohlin Visco 88 rotary viscometer (Malvern Panalytical, Malvern, UK) equipped with concentric cylinders. Apparent shear viscosity was recorded as a function of shear rate from 20 to $1230 \mathrm{~s}^{-1}$ and at various temperatures of $25^{\circ} \mathrm{C}, 30^{\circ} \mathrm{C}, 35^{\circ} \mathrm{C}$ and $40^{\circ} \mathrm{C}$. All solutions were equilibrated at constant temperature for $15 \mathrm{~min}$ before rheological tests. The power law model (Equation (5)) was used to fit the experimental viscosity curves [34,35]:

$$
\eta_{a}=k \dot{\gamma}^{n-1}
$$

In Equation (5), $k$ and $n$ are constants, $k$ is the consistency index $\left(\mathrm{Pa}^{\mathrm{n}}\right)$ and $n$ is the flow behavior index (dimensionless).

\subsection{FTIR Analysis}

IR spectra of the films were obtained with a Nicolet iS10 FTIR spectrophotometer Thermo Fisher Scientific Inc. (Waltham, MA, USA) using Attenuated Total Reflectance (ATR) mode with a diamond as the crystal. Each spectrum was obtained using 64 scans at a resolution of $2 \mathrm{~cm}^{-1}$, and a spectral range from 4000 to $600 \mathrm{~cm}^{-1}$. 


\section{Results and Discussion}

Figure 1 presents the Huggins plots (the reduced viscosity $\left(\eta_{s p} / c\right)$ vs. total concentration $\left.(c)\right)$ for HA and PVA and their blends at different HA weight fractions $\left(w_{H A}\right)$ in distilled water, $0.1 \mathrm{~mol} \mathrm{dm}^{-3} \mathrm{NaCl}$ and $0.1 \mathrm{~mol} \mathrm{dm}^{-3} \mathrm{HCl}$. All graphs present linear behavior for native polymers and HA/PVA blends over the entire composition range, suggesting that $[\eta]$ could be established by linear extrapolation to zero concentration. $[\eta]_{n}^{e x p}$ and $b_{m}^{\text {exp }}$ values were determined using the classical Huggins equation (Equation (2)) [30,31]. The ideal values $\left(b_{m}^{i d}\right)$ were calculated based on Garcia et al. [33]. $\Delta b_{m}$ and $\Delta[\eta]$ values and comparisons between the different solvents used in polymer systems are tabulated in Table 1 and Figure 2.
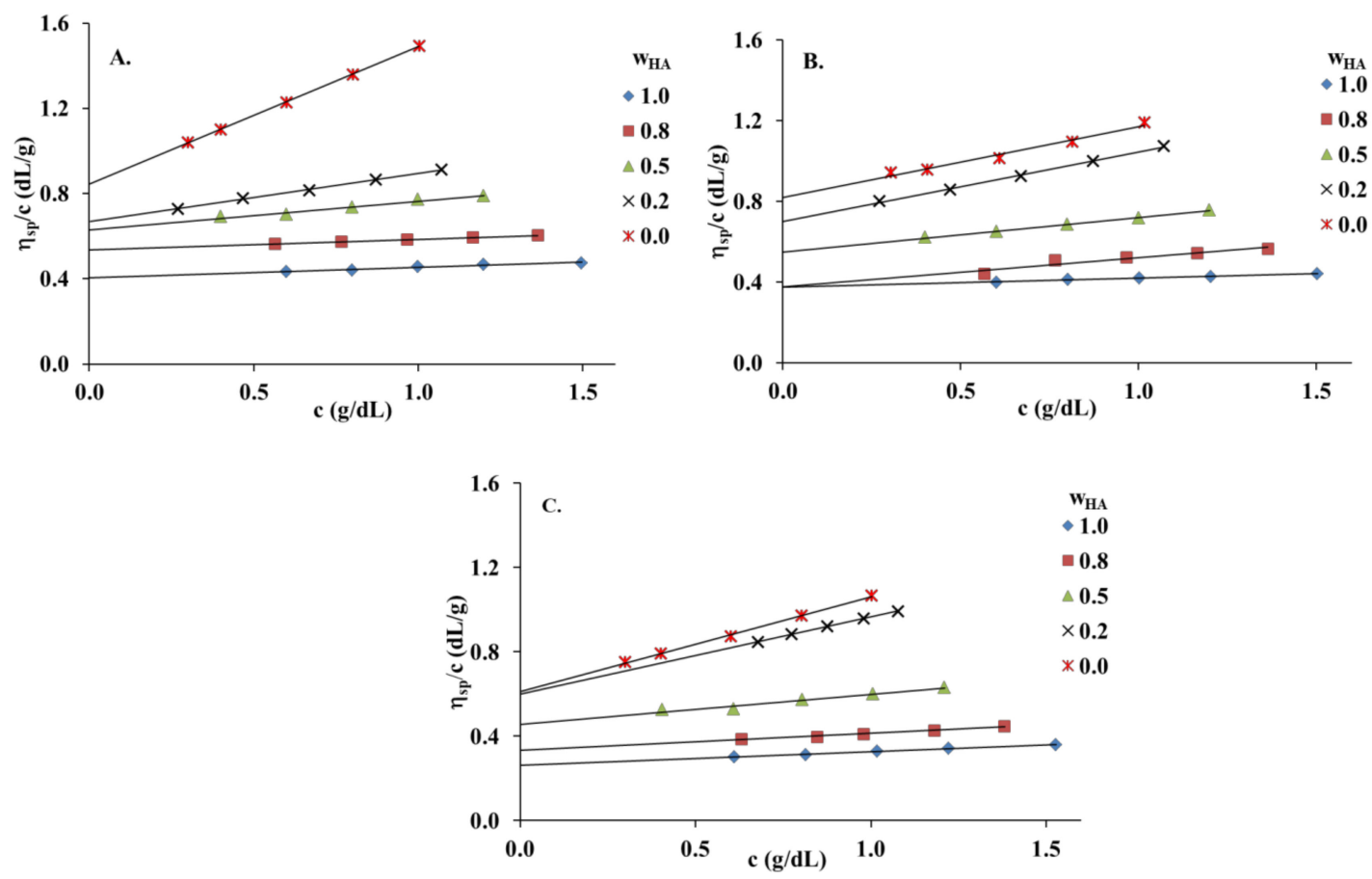

Figure 1. Reduced viscosity $\left(\eta_{s p} / \mathrm{c}\right)$ values of hyaluronic acid (HA), poly(vinyl alcohol) (PVA) and their blends at $25^{\circ} \mathrm{C}$ : (A) distilled water; (B) $0.1 \mathrm{~mol} \mathrm{dm}^{-3} \mathrm{NaCl}$; (C) $0.1 \mathrm{~mol} \mathrm{dm}{ }^{-3} \mathrm{HCl}$.

Table 1. Experimental and ideal miscibility parameters $b_{m}$ of HA/PVA blends.

\begin{tabular}{|c|c|c|c|c|}
\hline$w_{H A}$ & $\begin{array}{c}b_{m}^{\exp } \pm S D^{1} \\
(\mathrm{dL} / \mathrm{g})^{2}\end{array}$ & $\begin{array}{c}b_{m}^{i d} \pm S D \\
(\mathrm{dL} / \mathrm{g})^{2}\end{array}$ & $\Delta b_{m}$ & Remarks \\
\hline \multicolumn{5}{|c|}{ Solvent: Distilled Water } \\
\hline 0.2 & $0.228 \pm 0.021$ & $0.292 \pm 0.021$ & -0.0640 & immiscible \\
\hline 0.5 & $0.133 \pm 0.021$ & $0.125 \pm 0.021$ & 0.0080 & miscible \\
\hline 0.8 & $0.0502 \pm 0.021$ & $0.0492 \pm 0.021$ & 0.0010 & miscible \\
\hline \multicolumn{5}{|c|}{ Solvent: $0.1 \mathrm{NaCl} \mathrm{mol} \cdot \mathrm{dm}^{-3}$} \\
\hline 0.2 & $0.345 \pm 0.021$ & $0.226 \pm 0.021$ & 0.119 & miscible \\
\hline 0.5 & $0.175 \pm 0.021$ & $0.0989 \pm 0.021$ & 0.0711 & miscible \\
\hline 0.8 & $0.143 \pm 0.021$ & $0.0428 \pm 0.021$ & 0.100 & miscible \\
\hline \multicolumn{5}{|c|}{ Solvent: $0.1 \mathrm{HCl} \mathrm{mol} \cdot \mathrm{dm}^{-3}$} \\
\hline 0.2 & $0.367 \pm 0.021$ & $0.291 \pm 0.021$ & 0.0760 & miscible \\
\hline 0.5 & $0.143 \pm 0.021$ & $0.129 \pm 0.021$ & 0.0140 & miscible \\
\hline 0.8 & $0.0810 \pm 0.021$ & $0.0587 \pm 0.021$ & 0.0223 & miscible \\
\hline
\end{tabular}

${ }^{1} \mathrm{SD}$-standard deviation. 


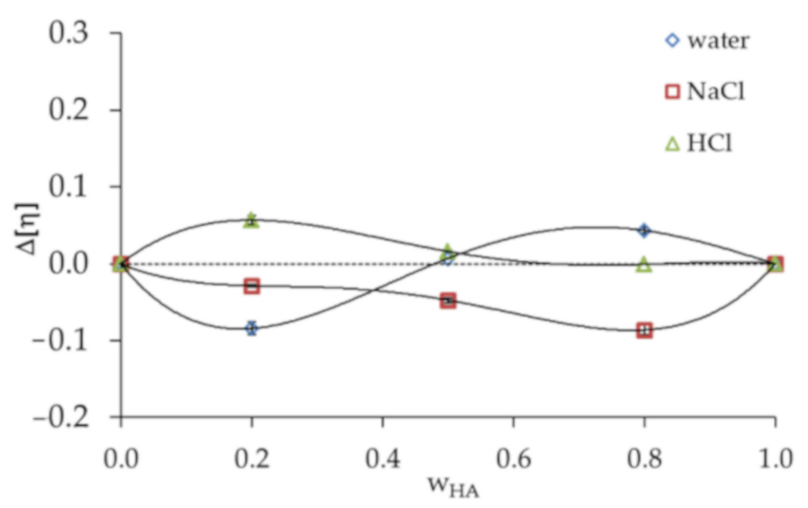

Figure 2. Plot of $\Delta[\eta]$ criterion versus HA weight fraction $\left(w_{H A}\right)$ in HA/PVA blends in various solvents.

The obtained results show that the differences in the $\Delta b_{m}$ and $\Delta[\eta]$ values in three solvents are significant. The values of the miscibility parameter $\left(\Delta b_{m}\right)$ are positive for all HA/PVA blends in 0.1 mol dm${ }^{-3} \mathrm{NaCl}$ and $0.1 \mathrm{~mol} \mathrm{dm}{ }^{-3} \mathrm{HCl}$, distinctly exceeding the range of experimental error. Hence, these blends satisfy the criterion proposed by Garcia et al. [33]. In the case of HA/PVA blends in distilled water, the miscibility parameters are negative or equal zero in the range of experimental errors, indicating the poorer miscibility of this solvent. The observed changes in the miscibility of $\mathrm{HA}$ and PVA are related to the polyelectrolyte nature of $\mathrm{HA}$. The addition of $\mathrm{NaCl}$ or $\mathrm{HCl}$ to the polymer solution causes increased ionic strength in the solution, resulting in reduced repulsive forces (electrostatic interactions) between molecules. Thus, the interaction of HA/PVA blends in $0.1 \mathrm{~mol}$ $\mathrm{dm}^{-3} \mathrm{NaCl}$ and $0.1 \mathrm{~mol} \mathrm{dm}{ }^{-3} \mathrm{HCl}$ mainly consists of hydrogen bonds. In turn, the immiscibility of polymeric components is related to repulsive forces which play a leading role in aqueous solutions without the addition of salt or acid. The greater amount of PVA in the HA solution promotes strong, repulsive interactions between the polymeric components and phase separation in the selected blend system $\left(w_{H A}=0.2\right)$, and is the reason for the negative value of the interaction parameter.

Garcia et al. [33] also proposed the criterion $\Delta[\eta]$; accordingly, all HA/PVA blends in $0.1 \mathrm{~mol} \mathrm{dm}^{-3}$ $\mathrm{NaCl}$ are miscible (Figure 2). In the case of $\mathrm{HA} / \mathrm{PVA}$ blends in $0.1 \mathrm{~mol} \mathrm{dm}^{-3} \mathrm{HCl}$, the experimental intrinsic viscosities are higher than ideal values. Attraction between HA and PVA in $0.1 \mathrm{~mol} \mathrm{dm}^{-3}$ $\mathrm{HCl}$ increase the hydrodynamic volume, causing positive deviation. The interaction between the two polymer components in this case is considered to be strong. If the interaction between polymer chains usually predominate over those between the polymer chain and the solvent, the result of attraction is a positive deviation from the ideal value. Interactions between polymer chains might decrease the opportunity for an interaction between the polymer chain and the solvent, weakening the solvation effect and causing the intrinsic viscosity to decrease. Thus, negative deviation is observed [36].

The effect of various solvents on the rheological properties of HA, PVA and their blends were investigated by steady shear measurements. Figures 3 and 4 show the viscosity curves as a function of the shear rate to the polymer samples and HA/PVA blends at $25^{\circ} \mathrm{C}$.

The apparent viscosity of HA solutions in distilled water and $0.1 \mathrm{~mol} \mathrm{dm}^{-3} \mathrm{NaCl}$ (Figure 3A) increase with the increasing shear rate, in which shear-thickening behavior is observed. However, in the aqueous acidic solution of HA, shear-thinning behavior (pseudoplastic nature) is observed; hence, the apparent viscosity decreases with increasing of shear rate. Moreover, the addition of $\mathrm{HCl}$ to the aqueous solution causes a marked increase in apparent viscosity. This may be attributed to the strong interactions and complex formations between active HA groups in the network structure and ion pairs with solvent. Furthermore, an increase in shear rate leads to destruction of the network structure and the dispersed HA molecules arrange along the flow direction. Thus, reduced apparent viscosity is observed. For PVA solutions in various solvents, the apparent viscosity of the solution decreases as the shear rate increases, showing a shear-thinning behavior. Moreover, no significant differences in apparent viscosity are observed in any solvent studied. Figure 4 presents the viscosity curves of HA/PVA solutions in various solvents. In HA/PVA blend solutions with $w_{H A} \leq 0.5$ in distilled water 
and $0.1 \mathrm{~mol} \mathrm{dm}^{-3} \mathrm{NaCl}$ as well as in all the blend solutions in $0.1 \mathrm{~mol} \mathrm{dm}^{-3} \mathrm{HCl}$, a shear-thinning behavior is observed (Figure 4). The pseudoplastic effect decreases with increasing PVA content in the blend solutions. Additionally, PVA and HA/PVA blend with $w_{H A}=0.2$ (Figure 4C) shows a flow pattern comparable to Newtonian behavior. In the case of the aqueous acidic solution of blends at $w_{H A} \geq 0.5$, the apparent viscosity is higher than that for pure polymer solutions, especially for a lower shear rate $\left(\dot{\gamma}<400 \mathrm{~s}^{-1}\right)$. This synergy could be explained by the attractive forces between the polymeric components in the blend solutions, promoting increased viscosity values. At a higher shear rate $(\dot{\gamma}>$ $400 \mathrm{~s}^{-1}$ ), shear forces destroy the hydrogen bonds that occur in the polymer blends and the observed differences are smaller.
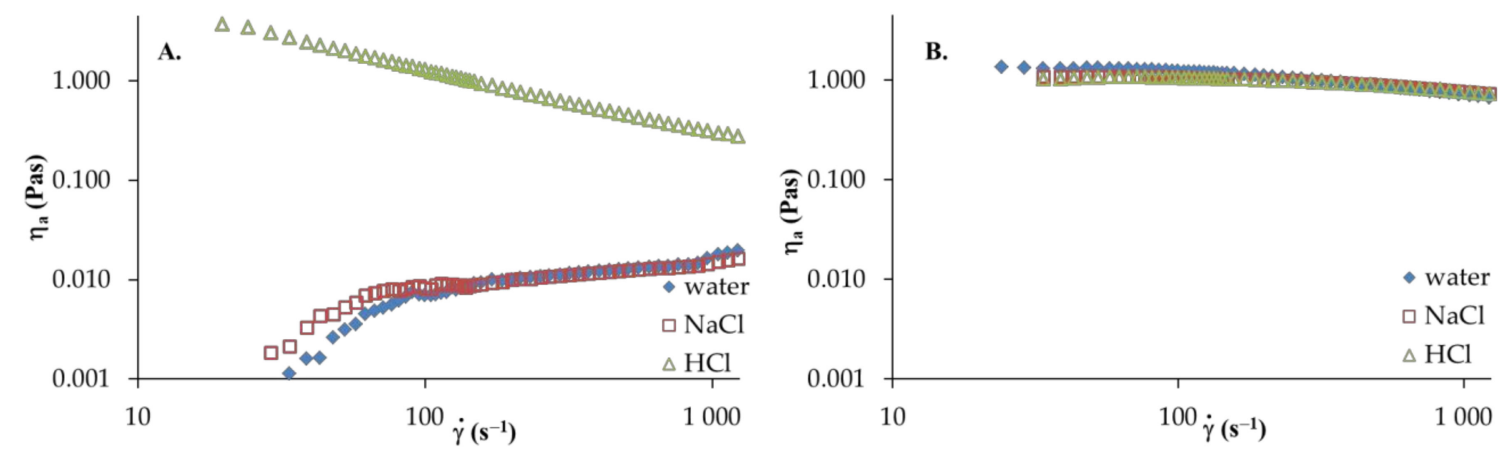

Figure 3. Apparent shear viscosity $a$ versus shear rate $\dot{\gamma}$ of HA and PVA: (A) HA and (B) PVA, T $=25$ ${ }^{\circ} \mathrm{C}$.

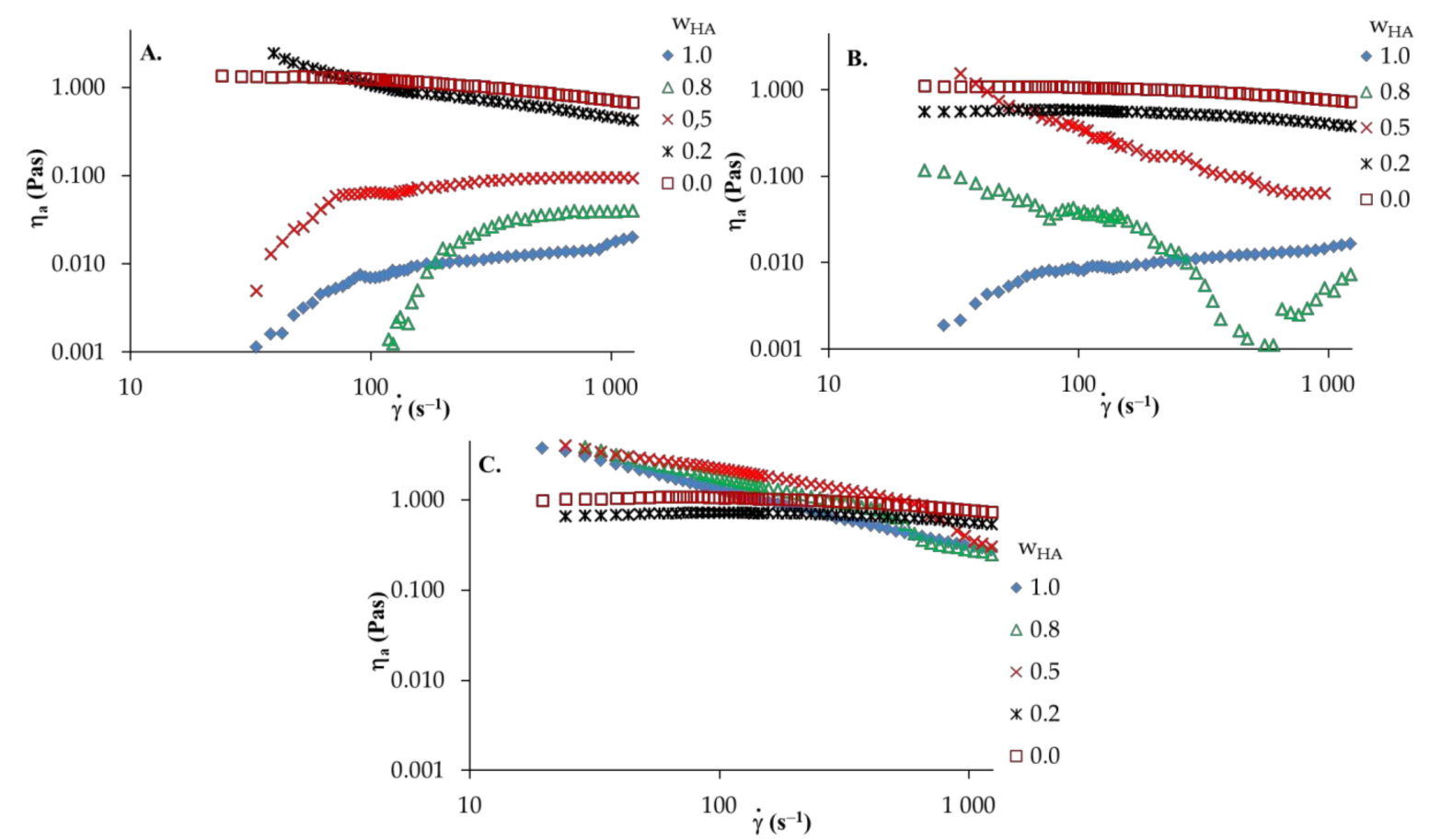

Figure 4. Apparent shear viscosity $a$ versus shear rate $\dot{\gamma}$ of HA and PVA and their blends: (A) distilled water; (B) $0.1 \mathrm{~mol} \mathrm{dm}{ }^{-3} \mathrm{NaCl}$; (C) $0.1 \mathrm{~mol} \mathrm{dm}^{-3} \mathrm{HCl}, \mathrm{T}=25^{\circ} \mathrm{C}, w_{\mathrm{HA}}-\mathrm{HA}$ weight fraction.

The experimental data were fitted with the power law model (Equation (5)) and the rheological parameters ( $n$ and $k$ ) were calculated using a linearized equation. The parameters for polymer solutions and their blends are listed in Table 2. In the case of non-Newtonian fluid $(n \neq 1)$, the viscosity characteristic can be approximately that of the shear-thinning behavior if $n<1$ and shear-thickening behavior if $n>1[35,37]$. Therefore, parameter values for $n$ of PVA and HA/PVA blend solutions with $w_{H A} \leq 0.5$ in distilled water and $0.1 \mathrm{~mol} \mathrm{dm}^{-3} \mathrm{NaCl}$ as well as all blend solutions in $0.1 \mathrm{~mol} \mathrm{dm}^{-3}$ 
$\mathrm{HCl}$ are below one, indicating that pseudoplastic behavior becomes more obvious with increasing $\mathrm{HA}$ content in the blend solutions. However, the PVA and HA/PVA blend with $w_{H A}=0.2$ in $0.1 \mathrm{~mol} \mathrm{dm}^{-3}$ $\mathrm{HCl}$ displays a value of the parameter $n$ that is approximate to one (Newtonian flow), especially for a higher temperature $\left(40^{\circ} \mathrm{C}\right)$. In the case of $\mathrm{HA}$ and HA/PVA blend solutions with $w_{H A} \geq 0.5$ in distilled water and $0.1 \mathrm{~mol} \mathrm{dm}^{-3} \mathrm{NaCl}$, where the shear thickening effect was observed, the parameter $n$ is above one, while, for the aqueous acidic solution of $\mathrm{HA}$, the value of the $n$ parameter is below one, indicating stronger shear-thinning property. The obtained low $n$ value suggests a high association degree and complex formation between components in solution. The consistency coefficients $k$ represent a direct relationship with the apparent viscosity. Therefore, $k$ coefficients are expected because the temperature commonly lowers the solution's viscosity. These observations are consistent with previous reports on HA or PVA solutions [37-40].

Table 2. The rheological parameters from power law model for HA, PVA and their blends as functions of temperature.

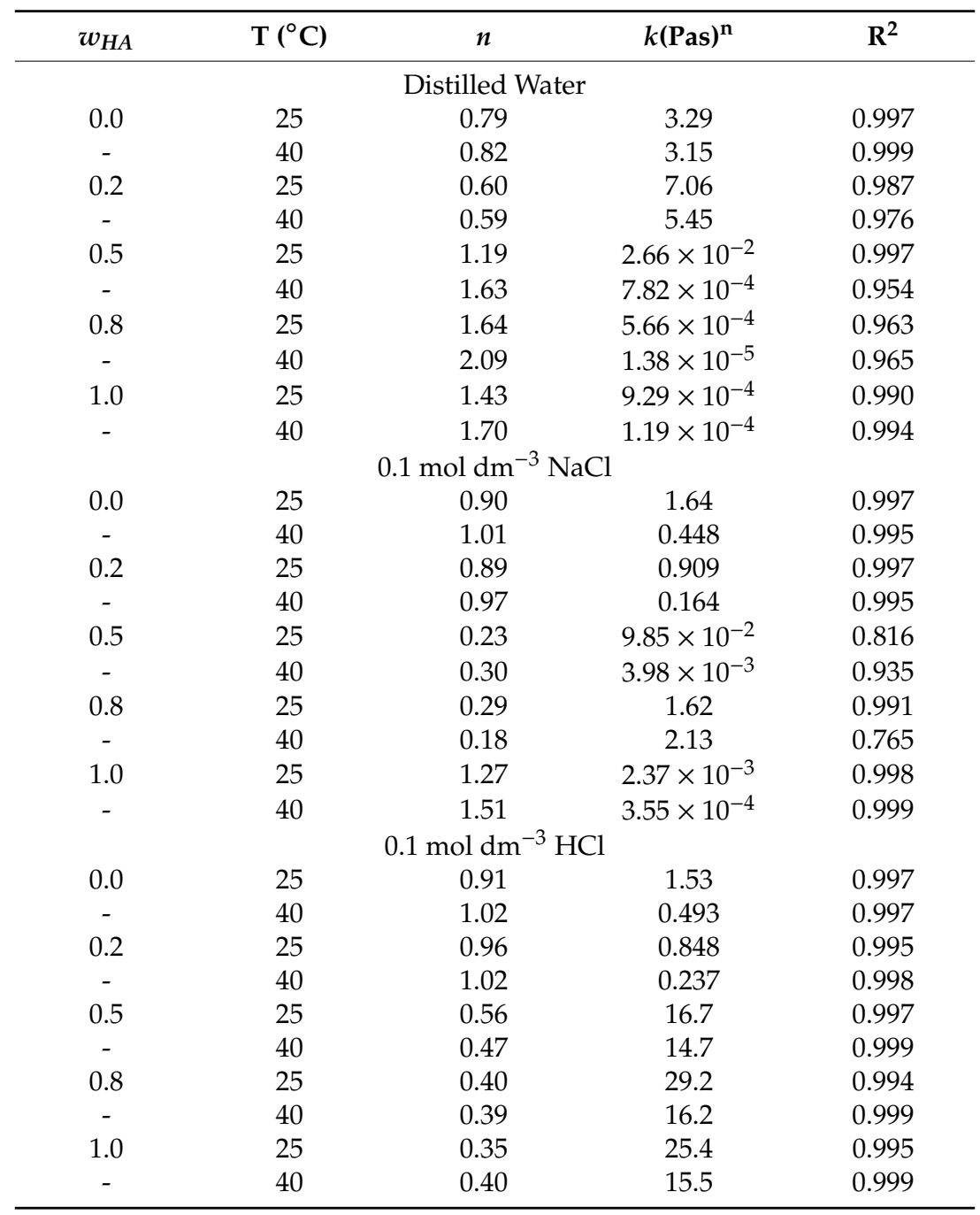

Figure 5 presents the logarithm of apparent viscosity $\left(\log \eta_{a}\right)$ for HA/PVA blends vs. HA weight fraction $\left(w_{H A}\right)$. The experimental $\log \eta_{a}$ values are drawn together with the values obtained according the additivity rule expressed by Equation (6):

$$
\log \eta_{m}=w_{A} \log \eta_{A}+w_{B} \log \eta_{B}
$$


where $\log \eta_{m}$ is the logarithm of the apparent shear viscosity of the polymer blend, $\log \eta_{A}$ and $\log \eta_{B}$ are the logarithms of the apparent shear viscosity of polymers A and B, respectively [41].

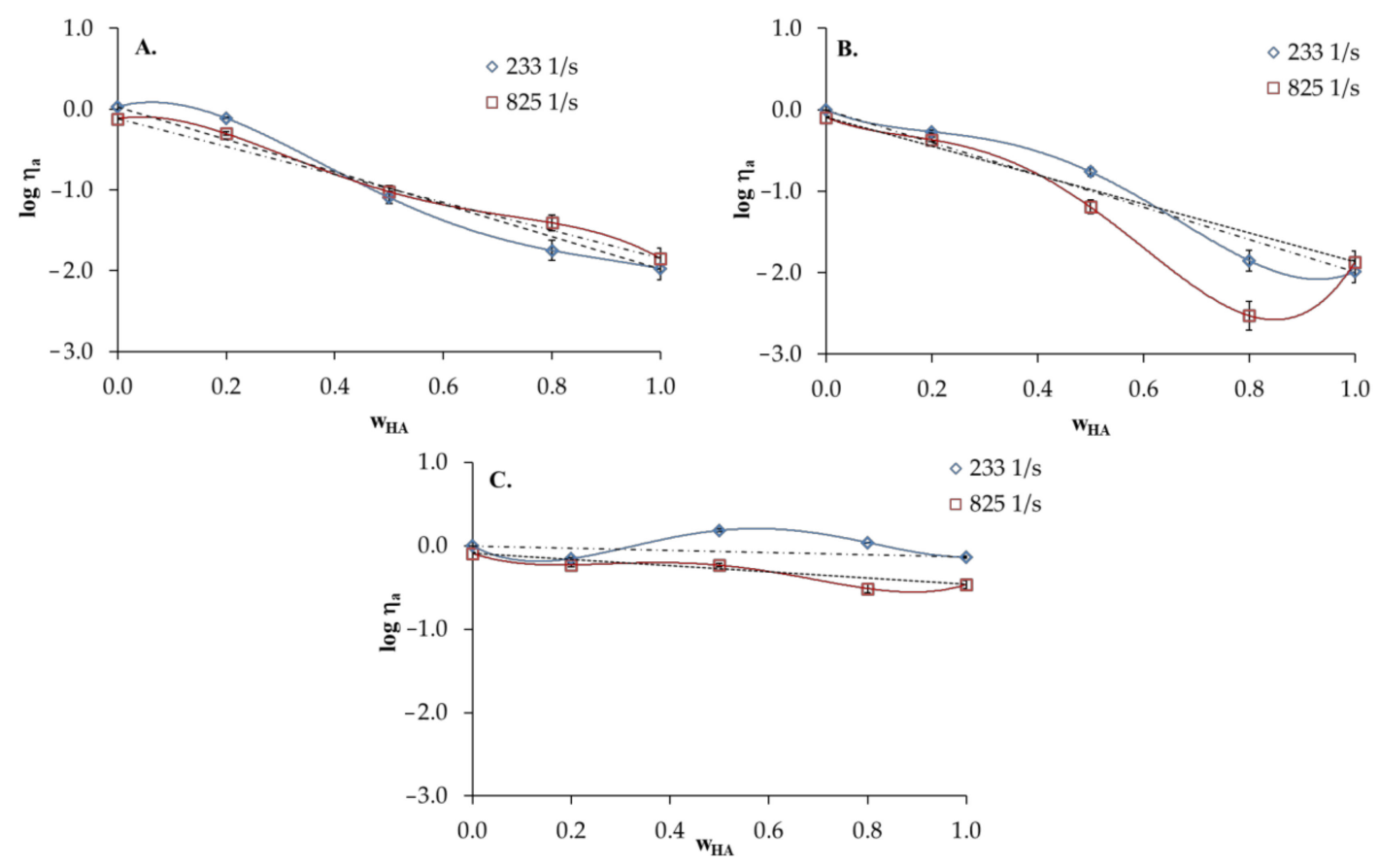

Figure 5. Logarithm of apparent shear viscosity of HA and PVA and their blends versus hyaluronic acid weight fraction $\left(w_{H A}\right)$ in the blends: (A) distilled water; (B) $0.1 \mathrm{~mol} \mathrm{dm}^{-3} \mathrm{NaCl}$; (C) $0.1 \mathrm{~mol} \mathrm{dm}^{-3}$ $\mathrm{HCl}, \mathrm{T}=25^{\circ} \mathrm{C}$, dotted line-values calculated according to the additivity rule.

As shown, the positive deviations from the calculated straight line illustrates the additivity rule of $0.1 \mathrm{~mol} \mathrm{dm}{ }^{-3} \mathrm{HCl}$. In the case of HA/PVA blends in distilled water, $\log \eta_{a}$ values practically fulfil the linear dependence drawn according to the additivity rule (Figure 5A). Deviations in the log $\eta_{a}$ decrease with the increasing shear rate, which is due to the destruction of intermolecular interactions between components under shear forces. HA/PVA blends in $0.1 \mathrm{~mol} \mathrm{dm}^{-3} \mathrm{NaCl}$ display negative deviations in $\log \eta_{a}$ from the additivity rule. This may indicate that HA and PVA are poorly miscible in $0.1 \mathrm{~mol}$ $\mathrm{dm}^{-3} \mathrm{NaCl}$.

FTIR is a method widely used to study polymer structures and to detect intermolecular interactions between polymer chains. Figure 6 shows the infrared spectra of pure components and their blends in distilled water and $0.1 \mathrm{~mol} \mathrm{dm}^{-3} \mathrm{HCl}$. Thus, FTIR allows for changes in the structure of HA/PVA blends, which is dependent on solvent and HA content. The spectrum of HA film was cast from distilled water and shows a broad absorption band at about $3310 \mathrm{~cm}^{-1}(\mathrm{OH}$ and $\mathrm{NH}$ stretching modes); the peak at $1610 \mathrm{~cm}^{-1}$ corresponds to carbonyl stretching bands of carboxylate [42,43]. An intense band extending between $900-1200 \mathrm{~cm}^{-1}$ corresponds to C-O stretching vibrations in alcohols $\left(1020 \mathrm{~cm}^{-1}\right.$ and $1080 \mathrm{~cm}^{-1}$ ), while the shoulder at $1152 \mathrm{~cm}^{-1}$ is assigned to C-O-C stretching vibrations in glycosidic groups [41]. In the spectrum of HA film cast from $0.1 \mathrm{~mol} \mathrm{dm}^{-3} \mathrm{HCl}$ solution, amide I and II bands are observed at $1644 \mathrm{~cm}^{-1}$ and $1562 \mathrm{~cm}^{-1}$ (marked with an asterisk) in which the asymmetric of stretching carboxylate groups greatly decreased. The peak at $1730 \mathrm{~cm}^{-1}$ relates to the carbonyl stretching bands of carboxyl groups in HA film $[4,42,43]$. Therefore, most of the carboxyl groups are protonated in acidic HA solution $[42,44,45]$. For PVA films, the spectra show the peaks of the stretching vibration of $\mathrm{OH}$ groups at $3280 \mathrm{~cm}^{-1}$ or $3270 \mathrm{~cm}^{-1}$ and C-O stretching vibrations in the range of $900-1200 \mathrm{~cm}^{-1}$. 

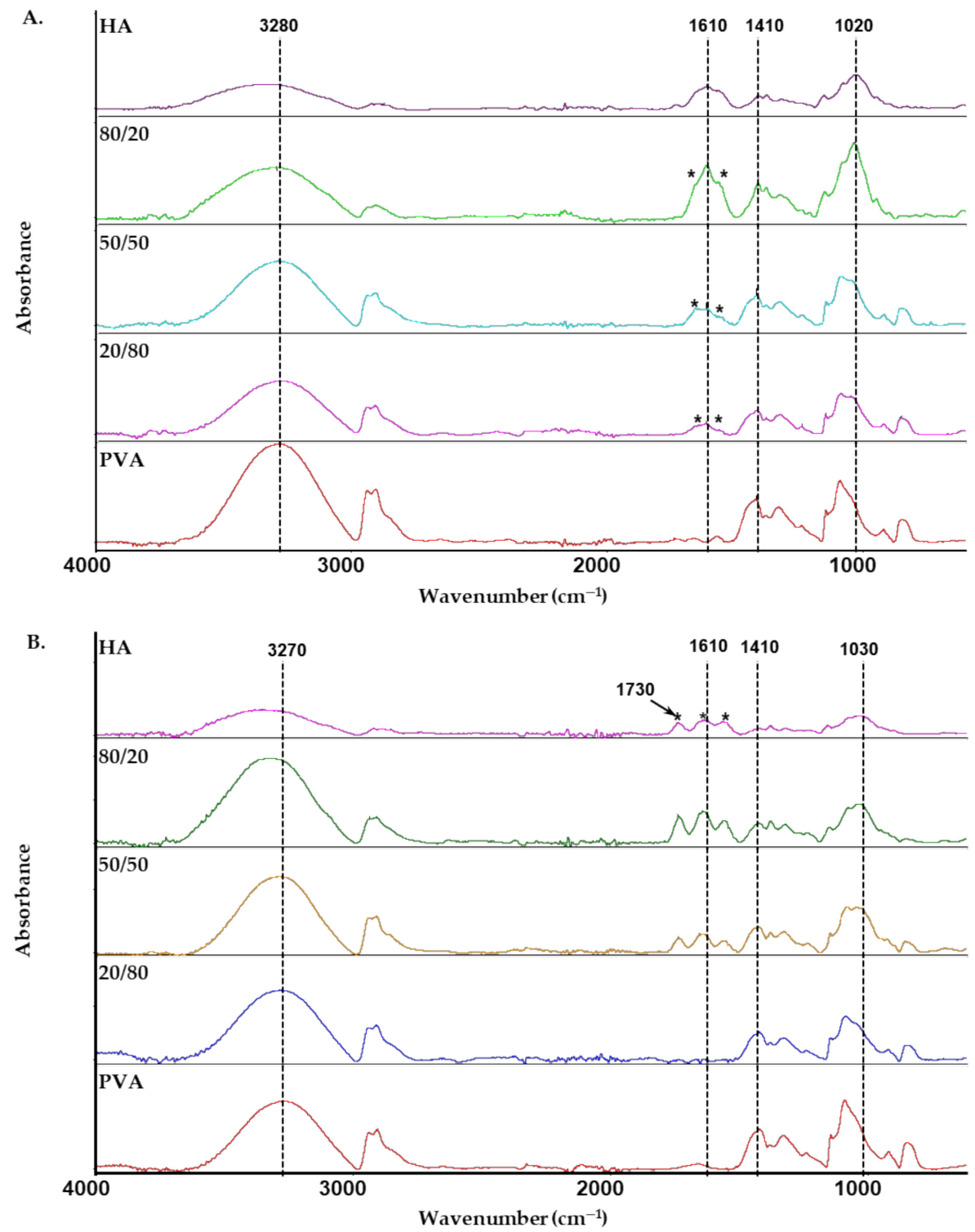

Figure 6. Attenuated Total Reflectance (ATR)-infrared spectra of HA, PVA and their blend films in various solvents: (A) distilled water; (B) $0.1 \mathrm{~mol} \mathrm{dm}^{-3} \mathrm{HCl}$.

The interactions occurring in HA/PVA blend films between the components are visible by marked spectral changes, especially in the region of the stretching vibration of $\mathrm{OH}$ groups, the $\mathrm{C}-\mathrm{O}$ stretching vibrations in alcohols and the amide I and II bands. The maximum of the $\mathrm{OH}$ stretching band of the HA/PVA blends is located between that corresponding to HA $\left(3340 \mathrm{~cm}^{-1}\right.$ or $\left.3310 \mathrm{~cm}^{-1}\right)$ and PVA (3280 $\mathrm{cm}^{-1}$ or $3270 \mathrm{~cm}^{-1}$ ). The spectra of blend films cast from distilled water show that two sub-bands at approximately $1653 \mathrm{~cm}^{-1}$ and $1552 \mathrm{~cm}^{-1}$ are intense (marked with an asterisk) and can be attributed to carboxylate groups of HA participating in one or more hydrogen bonds [42,44]. Additionally, the wide band at approximately $1020 \mathrm{~cm}^{-1}$ shifts after blending HA with PVA, possibly due to interactions between - $\mathrm{COO}^{-}$and $-\mathrm{OH}$ groups of $\mathrm{HA}$ and $-\mathrm{OH}$ groups of PVA. For blend films cast from $0.1 \mathrm{~mol}$ $\mathrm{dm}^{-3} \mathrm{HCl}$ solution, the spectra of HA/PVA blends with $w_{H A} \geq 0.5$ showed bands at $1730 \mathrm{~cm}^{-1}$ and $1640 \mathrm{~cm}^{-1}$ corresponding to the -COOH groups of HA. These bands are not observed for the blend with low HA content. Thus, the results suggest that other functional groups such as $-\mathrm{NHCOCH}_{3}$ can form hydrogen bonds with -OH groups of PVA and create miscible blends. These results are consistent with viscosity and rheological studies which indicate that the blend is miscible. FTIR spectroscopy 
analysis confirmed the formation of new interactions between the HA and PVA which influenced the viscosity behavior and observed synergistic effects.

\section{Conclusions}

Herein, the impact of the solvent on the miscibility of HA/PVA blends using the viscometric method, steady shear rheological measurements and FTIR analysis have been investigated. It was found that solvent has a large effect on the viscosity behavior. HA/PVA blends are completely miscible due to the attractive forces through hydrogen bonding in $0.1 \mathrm{~mol} \mathrm{dm}{ }^{-3} \mathrm{NaCl}$ and $0.1 \mathrm{~mol} \mathrm{dm}^{-3} \mathrm{HCl}$. The miscibility of HA with PVA is related to HA conformation changes and interactions driven by hydrogen bonding between $-\mathrm{COOH}$ and $-\mathrm{NHCOCH}_{3}$ groups in $\mathrm{HA}$ and $-\mathrm{OH}$ groups in PVA. Analyses of the rheological properties show that the HA/PVA blends at $w_{H A} \geq 0.5$ in $0.1 \mathrm{~mol} \mathrm{dm}^{-3} \mathrm{HCl}$ exhibit a larger apparent viscosity than native polymers. Therefore, interactions between HA and PVA and positive synergistic effects that occur in aqueous acidic solutions are significant. HA and PVA are potential candidates for the preparation of new functional materials. Additionally, they play a key role in the properties of the resulting polymer blends for different applications, including tissue engineering, wound dressings, drug delivery systems, and cosmetics.

Funding: This research received no external funding. The APC was funded by Nicolaus Copernicus University in Toruń ("Excellence Initiative-Research University" programme).

Conflicts of Interest: The author declares no conflict of interest.

\section{References}

1. Rinaudo, M. Review: Main properties and current applications of some polysaccharides as biomaterials. Polym. Int. 2008, 57, 397-430. [CrossRef]

2. Schanté, C.E.; Zuber, G.; Herlin, C.; Vandamme, T.F. Review: Chemical modifictions of hyaluronic acid for the synthesis of derivatives for a broad range of biomedical applications. Carbohydr. Polym. 2011, 85, 469-489. [CrossRef]

3. Collins, M.N.; Birkinshaw, C. Hyaluronic acid based scaffolds for tissue engineering-A review. Carbohydr. Polym. 2013, 92, 1262-1279. [CrossRef] [PubMed]

4. Vasi, A.M.; Popa, M.I.; Butnaru, M.; Dodi, G.; Verestiuc, L. Chemical functionalization of hyaluronic acid for drug delivery applications. Mater. Sci. Eng. C 2014, 38, 177-185. [CrossRef] [PubMed]

5. Hemshekhar, M.; Thushara, R.M.; Chandranayaka, S.; Sherman, L.S.; Kemparaju, K.; Girish, K.S. Emerging roles of hyaluronic acid bioscaffolds in tissue engineering and regenerative medicine. Int. J. Biol. Macromol. 2016, 86, 917-928. [CrossRef] [PubMed]

6. Dutta, R.C.; Dey, M.; Dutta, A.K.; Basu, B. Competent processing techniques for scaffolds in tissue engineering. Biotechnol. Adv. 2017, 35, 240-250. [CrossRef] [PubMed]

7. Naahidi, S.; Jafari, M.; Logan, M.; Wang, Y.; Yuan, Y.; Bae, H.; Dixon, B.; Chen, P. Biocompatibility of hydrogel-based scaffolds for tissue engineering applications. Biotechnol. Adv. 2017, 35, 530-544. [CrossRef]

8. von Lospichl, B.; Hemmati-Sadeghi, S.; Dey, P.; Dehne, T.; Haag, R.; Sittinger, M.; Ringe, J.; Gradzielski, M. Injectable hydrogels for treatment of osteoarthritis-A rheological study. Colloid. Surf. B Biointerfaces 2017, 159, 477-483. [CrossRef]

9. Rebelo, R.; Fernandes, M.; Fangueiro, R. Biopolymers in Medical Implants: A Brief Review. Procedia Eng. 2017, 200, 236-243. [CrossRef]

10. Hussain, A.; Zia, K.; Tabasum, S.; Noreen, A.; Ali, M.; Iqbal, R.; Zuber, M. Blends and composites of exopolysaccharides; properties and applications: A review. Int. J. Biol. Macromol. 2017, 94, 10-27. [CrossRef]

11. Sionkowska, A.; Kaczmarek, B.; Michalska, M.; Lewandowska, K.; Grabska, S. Preparation and characterization of collagen/chitosan/hyaluronic acid thin films for application in hair care cosmetics. Pure Appl. Chem. 2017, 89, 1829-1839. [CrossRef]

12. Chanda, A.; Adhikari, J.; Ghosh, A.; Chowdhury, S.R.; Thomas, S.; Datta, P.; Saha, P. Electrospun chitosan/polycaprolactone-hyaluronic acid bilayered scaffold for potential wound healing applications. Int. J. Biol. Macromol. 2018, 116, 774-785. [CrossRef] [PubMed] 
13. Fallacara, A.; Marchetti, F.; Pozzoli, M.; Citernesi, U.R.; Manfredini, S.; Vertuani, S. Formulation and characterization of native and crosslinked hyaluronic acid microspheres for dermal delivery of sodium ascorbyl phosphate: A comparative study. Pharmaceutics 2018, 10, 254. [CrossRef] [PubMed]

14. Yu, L.; Dean, K.; Li, L. Polymer blends and composites from renewable resources. Prog. Polym. Sci. 2006, 31, 576-602. [CrossRef]

15. Sionkowska, A. Current research on the blends of natural and synthetic polymers as new biomaterials: Review. Prog. Polym. Sci. 2011, 36, 1254-1276. [CrossRef]

16. Chiellini, E.; Corti, A.; D'Antone, S.; Solaro, R. Biodegradation of poly(vinyl alcohol) based materials. Prog. Polym. Sci. 2003, 28, 963-1014. [CrossRef]

17. Baker, M.I.; Walsh, S.P.; Schwartz, Z.; Boyan, B.D. A review of polyvinyl alcohol and its uses in cartilage and orthopedic applications. J. Biomed. Mater. Res. Part. B Appl. Biomater. 2012, 100B, 1451-1457. [CrossRef]

18. Rafique, A.; Zia, K.M.; Zuber, M.; Tabasum, S.; Rehman, S. Chitosan functionalized poly(vinyl alcohol) for prospects biomedical and industrial applications: A review. Int. J. Biol. Macromol. 2016, 87, 141-154. [CrossRef]

19. Brunchi, C.R.; Bercea, M.; Morariu, S.; Avadanei, M. Investigations on the interactions between xanthan gum and poly(vinyl alcohol) in solid state and aqueous solutions. Eur. Polym. J. 2016, 84, 161-172. [CrossRef]

20. Teodorescu, M.; Bercea, M.; Morariu, S. Biomaterials of PVA and PVP in medical and pharmaceutical applications: Perspective and challenges. Biotechnol. Adv. 2019, 37, 109-131. [CrossRef]

21. Pan, N.C.; Bersaneti, G.T.; Mali, S.; Colabone Celligoi, M.A.P. Films based on blends of polyvinyl alcohol and microbial hyaluronic acid. Braz. Arch. Biol. Technol. 2020, 63, 1-14. [CrossRef]

22. Pirinen, S.; Karvinen, J.; Tiitu, V.; Suvanto, M.; Pakkanen, T.T. Control of swelling properties of polyvinyl alcohol/hyaluronic acid hydrogel for the encapsulation of chondrocyte cells. J. Appl. Polym. Sci. 2015, 132, 1-6. [CrossRef]

23. Kodavaty, J.; Desphpande, A.P. Self-assembly and drying assisted microstructural domain formation in poly(vinyl alcohol) and hyaluronic acid gels. Polym. Bull. 2017, 74, 3605-3617. [CrossRef]

24. Ramya, K.A.; Srinivasan, R.; Deshpande, A.P. Nonlinear measures and modelling to examine the role of physical and chemical crosslinking in poly(vinyl alcohol)-based crosslinked systems. Rheol. Acta 2018, 57, 181-195. [CrossRef]

25. Fahmy, A.; Kamoun, E.A.; El-Eisawy, R.; El-Fakharany, E.M.; Taha, T.H.; El-Damhougy, B.K. Poly(vinyl)-hyaluronic acid membrances for wound dressing applications: Synthesis and in-vitro bio-evalutions. J. Braz. Chem. Soc. 2015, 26, 1466-1474.

26. Yilmaz, C.N.C.; Pamfil, D.; Vasile, C.; Bibire, N.; Lupusoru, R.V.; Zamfir, C.L. Toxicity, biocompatibility, pH responsiveness and methotrexate release for pva/hyaluronic crygels for psoriasis therapy. Polymers 2017, 9 , $1-19$.

27. Kuchaiyaphum, P.; Rifai, G.; Yuuki, W.; Yamauchi, T. Hyaluronic acid-poly(vinyl alcohol) composite cryogel for biofunctional material application. Polym. Adv. Technol. 2019, 30, 94-100. [CrossRef]

28. Kim, S.H.; Hyun, K.; Moon, T.S.; Mitsumata, T.; Hong, J.S.; Ahn, K.H. Morphology-rheology relationship in hyaluronate/poly(vinyl alcohol)/borax polymer blends. Polymer 2005, 46, 7156-7163. [CrossRef]

29. Sionkowska, A.; Lewandowska, K.; Płanecka, A. Miscibility and physical properties of chitosan and silk fibroin mixtures. J. Mol. Liq. 2014, 198, 354-357. [CrossRef]

30. Huggins, M.H. The viscosity of dilute solutions of long-chain molecules. IV Dependence on concentration. J. Am. Chem. Soc. 1942, 64, 2716-2718. [CrossRef]

31. Bohdanecký, M.; Kovář, I. Viscosity of Polymer Solution; Jenkins, A.D., Ed.; Elsevier Science: Amsterdam, The Netherlands, 1982; Volume 2, pp. 167-186.

32. Lewandowska, $\mathrm{K}$. The miscibility of poly(vinyl alcohol)/poly(N-vinylpyrrolidone) blends investigated in dilute solutions and solids. Eur. Polym. J. 2005, 41, 55-64. [CrossRef]

33. Garcia, R.; Melad, O.; Gómez, C.M.; Figueruelo, J.E.; Campos, A. Viscometric study on the compatibility of polymer-polymer mixtures in solution. Eur. Polym. J. 1999, 35, 47-55. [CrossRef]

34. Tian, Z.; Duan, L.; Wu, L.; Shen, L.; Li, G. Rheological properties of glutaraldehyde-crosslinked collagen solutions analysed quantitatively using mechanical models. Mater. Sci. Eng. C 2016, 63, 10-17. [CrossRef] [PubMed]

35. Wang, B.; Qiao, C.; Gao, X.; Yang, X.; Li, Y.; Li, T. Rheological properties of N-[(2-hydroxyl)-propyl-3-trimethyl ammonium] chitosan chloride. Carbohydr. Polym. 2017, 171, 50-58. [CrossRef] 
36. Pingping, Z.; Haiyang, Y.; Shiqiang, W. Viscosity behaviour of poly-e-caprolactone (PCL)/poly(vinyl chloride) (PVC) blends in various solvents. Eur. Polym. J. 1998, 34, 91-94. [CrossRef]

37. Garcia-Abuin, A.; Gomez-Diaz, D.; Navaza, J.M.; Regueiro, L.; Vidal-Tato, I. Viscosimetric behaviour of hyaluronic acid in different aqueous solutions. Carbohydr. Polym. 2011, 85, 500-505. [CrossRef]

38. Martin, A.A.; Sassaki, G.L.; Sierakowska, M.R. Effect of adding galactomannans om some physical and chemical properties of hyaluronic acid. Int. J. Biol. Macromol. 2020, 144, 527-535. [CrossRef]

39. Mucha, M. Rheological properties of chitosan blends with poly(ethylene oxide) and poly(vinyl alcohol) in solution. React. Funct. Polym. 1998, 38, 19-25. [CrossRef]

40. Lewandowska, K.; Dabrowska, A.; Kaczmarek, H. Rheological properties of pectin, poly(vinyl alcohol) and their blends in aqueous solutions. e-Polymers 2012, 12, 1-13. [CrossRef]

41. Viswanath, D.S.; Gosh, T.K.; Prasad, D.H.L.; Dutt, N.V.K.; Rani, K.Y. Chapter 5: Viscosities of solution and mixtures. In Viscosity of Liquids: Theory, Estimation, Experiment and Data; Springer: Dordrecht, The Netherlands, 2007; pp. 427-428.

42. Haxaire, K.; Maréchal, Y.; Milas, M.; Rinaudo, M. Hydration of polysaccharide hyaluronan observed by IR spectrometry. I. Preliminary experiments and band assignments. Biopolymers 2003, 72, 10-20. [CrossRef]

43. Lee, E.J.; Kang, E.S.; Kang, W.; Huh, K.M. Thermo-irreversible glycol chitosan/hyaluronic acid blend hydrogel for injectable tissue engineering. Carbohydr. Polym. 2020, 244, 116432. [CrossRef] [PubMed]

44. Cai, Z.; Zhang, F.; Wei, Y.; Zhang, H. Freeze-thaw-induced gelation of hyaluronan: Physical cryostructuration correlated with intermolecular associations and molecular conformation. Macromolecules 2017, 50, 6647-6658. [CrossRef]

45. Lopes, T.D.; Riegel-Vidotti, I.C.; Grein, A.; Tischer, C.A.; de Sousa Faria-Tischer, P.C. Bacterial cellulose and hyaluronic acid hybrid membranes: Production and characterization. Int. J. Biol. Macromol. 2014, 67, 401-408. [CrossRef] [PubMed]

Publisher's Note: MDPI stays neutral with regard to jurisdictional claims in published maps and institutional affiliations.

(C) 2020 by the author. Licensee MDPI, Basel, Switzerland. This article is an open access article distributed under the terms and conditions of the Creative Commons Attribution (CC BY) license (http://creativecommons.org/licenses/by/4.0/). 